\title{
A memória e o autoconhecimento nas vivências ambientais urbanas enquanto proposta educativa
}

\author{
Memory and self-knowledge in urbanenvironmental experiences \\ as an educational proposal
}

\section{Memoria y autoconocimiento en experiencias ambientales. como propuesta educative}

\author{
Lakshmi Juliane Vallim Hofstatter ${ }^{1}$ \\ Haydée Torres de Oliveira ${ }^{2}$
}

\begin{abstract}
Resumo
Diante do fato de a maior parte da população brasileira viver nas cidades, procuramos melhor compreender quais são os caminhos experenciados na infância e vividos por pessoas que possuem vínculos afetivos com áreas verdes urbanas. Trabalhamos, individualmente, com nove estudantes universitários, na perspectiva fenomenológica, entrevistando e realizando atividades conjuntamente em lugares eleitos como tendo significado afetivo na cidade de Salvador, BA, o que oportunizou momentos reflexivos de autoconhecimento às pessoas participantes. Percebemos, através de suas memórias, a importância desses lugares no engajamento que essas pessoas têm com e no mundo, pois a convivência desde a infância nos ambientes naturais, na cidade, influenciou em suas escolhas de vida. Destacamos a importância das áreas verdes urbanas acessíveis à toda população e a possibilidade de trabalhar a memória e o autoconhecimento nas práticas ambientais educativas enquanto forma de revisitar nossos elos ambientais e, também, fortificá-los através de novas vivências.
\end{abstract}

Palavras-chaves: Áreas verdes urbanas. Memórias afetivas. Entrevista em movimento.

\begin{abstract}
In view of the fact that most of the Brazilian population lives in cities, we tried to better understand the paths trodden by people who have affective ties to urban nature. We worked individually with nine university students. We interviewed and took a walk together in places they related feeling an affection to in Salvador city (BahiaBrazil). We perceived the importance of these places in the engagements to and in the world, since the coexistence since the childhood in the natural environments in the city influenced the professional choice and the way they handle life. We found that even that people feel less immersed in urban nature, it is nature that brings the emotional memory back when people visit the places where they grew up. We emphasize the importance of urban green areas accessible to the entire population and the possibility of working with memory and self-knowledge in environmental educational practices as a way of reaffirming and revisiting our environmental links.
\end{abstract}

Keywords: Urban green areas. Emotional memories. Walking interview.

\section{Resumen}

La mayoria de la población brasileña vive en ciudades, por lo que tratamos de comprender mejor cuáles son los caminos experimentados en la infancia y vividos por personas que tienen vínculos afectivos con las áreas verdes urbanas. Trabajamos individualmente con nueve estudiantes universitarios, desde una perspectiva fenomenológica, entrevistando y realizando actividades juntos, en lugares elegidos como de significado afectivo en la ciudad de Salvador/BA, lo que proporcionó momentos reflexivos de autoconocimiento a los participantes. A través de sus recuerdos, nos damos cuenta de la importancia de estos lugares en el comprometimiento que estas

\footnotetext{
${ }^{1}$ Doutora em Ciências pelo Programa de pós-graduação em Ecologia e Recursos Naturais da Universidade Federal de São Carlos. Professora do Instituto Federal de Educação, Ciência e Tecnologia Baiano, Campus Catu. E-mail: lakshmivallim@gmail.com

2 Professora Titular/Sênior. Laboratório de Educação Ambiental. Departamento de Ciências Ambientais, Universidade Federal de São Carlos. E-mail: haydee.ufscar@gmail.com
} 
personas tienen con y en el mundo, ya que la convivencia desde la infancia en los entornos naturales, en la ciudad, influyó en sus elecciones de vida. Destacamos la importancia de las áreas verdes urbanas, accesibles a toda la población y la posibilidad de trabajar con memoria y autoconocimiento en las practicas ambientales educativas como una forma de revisar nuestros vínculos ambientales, además de profundizalos a través de nuevas experiencias.

Palabras clave: Áreas verdes urbanas. Memorias afectivas. Entrevista en la marcha.

\section{Introdução}

A população, nas cidades brasileiras, vêm crescendo consideravelmente desde a década de 1950, com a intensificação do exôdo rural e aumento da urbanização das cidades. É importante destacar que, segundo os dados do censo do Instituto Brasileiro de Geografia e Estatística (IBGE) de 2010, aproximadamente $85 \%$ da população brasileira é urbana. No mundo, segundo um relatório de 2014 sobre a perspectiva da urbanização mundial, realizado pela Organização das Nações Unidas, $54 \%$ das pessoas vivem em áreas urbanas, uma proporção que se espera venha a aumentar para 66\% até 2050 (UNRIC, s/d). Dentro dessa perspectiva, Salvador, capital do estado da Bahia, é um município de população predominantemente urbana e altos índices de concentração demográfica (IBGE, 2010). Os altos índices de urbanização atingidos em nosso país, incluindo Salvador, apontam apontam para a necessidade da implantação de áreas verdes urbanas para melhoria da qualidade de vida, em diversos aspectos. De fato, segundo a Sociedade Brasileira de Arborização Urbana - SBAU estima, que as cidades devem possuir $15 \mathrm{~m}^{2}$ de área verde por habitante (SBAU, 1996).

Um estudo realizado em Salvador, a partir de fotos de satélite, revela que o município possui percentual de cobertura vegetal em torno de $28,40 \%$, que equivale a um índice de $32,21 \mathrm{~m}^{2}$ de áreas verdes por habitante. Porém, quando se analisa a distribuição por bairros, percebe-se a concentração das áreas verdes em poucos espaços da cidade, pois os percentuais de cobertura vegetal variam entre 0 e 73,64\%. Entre os 163 bairros analisados na cidade, 108 possuem um índice de arborização por habitante inferior ao recomendado pela SBAU, destacando trinta bairros onde esse índice não alcança $1 \mathrm{~m}^{2}$ por habitante e quatro bairros que possuem índice de $0 \%$ de cobertura vegetal, conforme dados dessa pesquisa realizada em 2009 (OLIVEIRA et al., 2013).

De acordo com o Art. $8^{\circ}, \S^{\circ}$, da Resolução Conama $n^{\circ} 369$, define-se como área verde "o espaço de domínio público que desempenhe função ecológica, paisagística e recreativa, propiciando a melhoria da qualidade estética, funcional e ambiental da cidade, sendo dotado de vegetação e espaços livres de impermeabilização" (BRASIL, 2006). Já o Ministério do Meio Ambiente - MMA apresenta a seguinte definição de áreas verdes: "são consideradas como o conjunto de áreas intraurbanas que apresentam cobertura vegetal, arbórea (nativa e introduzida), arbustiva ou rasteira (gramíneas) e que contribuem de modo significativo para a qualidade de vida e o equilíbrio ambiental nas cidades" (MMA, s/d ${ }^{3}$ ). O site do MMA cita como exemplos dessas áreas: praças, parques urbanos, parques fluviais, parque balneário e esportivo; jardins botânicos; jardins zoológicos; alguns tipos de cemitérios e as faixas de ligação entre áreas verdes.

Vivemos projetos urbanísticos que não priorizam as áreas verdes, que elegem o concreto nas construções, que enclausuram os rios, suprimem a vegetação e afastam ou eliminam a fauna, e consideramos importante compreender como estão se estabelecendo as relações humanas com a natureza nas áreas urbanas. E, apesar de sermos natureza, é desafiador o processo de integração entre nós, seres humanos, com o ambiente natural no contexto urbano. Muitas pessoas se distanciaram do sentimento de pertencimento e conexão à natureza e não se sentem

\footnotetext{
${ }^{3}$ Disponível na site do Ministério do Meio Ambiente: http://www.mma.gov.br/informma/itemlist/category/61-areas-verdes$\underline{\text { urbanas }}$
} 
responsáveis pelo cuidado ao meio ambiente, estabelecendo altos padrões de consumo de bens e recursos naturais.

Entretanto, mesmo diante desse afastamento, percebemos que os seres humanos possuem vínculos com o seu meio. Contemplamos, assim, o conceito de topofilia, que define a existência de um "elo afetivo entre a pessoa e o lugar ou ambiente físico" (TUAN, 2012, p. 19). E, enfatizamos, que para Tuan (2013), o lugar é construído a partir da experiência e dos sentidos, o que é diferente de espaço ${ }^{4}$. A partir desse entendimento de Tuan (2012), acatamos a diferenciação de espaço e lugar. Contudo, valorizamos o espaço para novas possibilidades de vivências, pois a partir do vazio ou daquilo que ainda não contém uma ligação afetiva, existe a potencialidade de acontecer novas experiências ou a (re)invenção de formas de apropriação dos locais.

Nesse sentido, Thrift (2008) emprega o termo tecido ao considerar o espaço enquanto algo aberto e não como algo que se encerra, lembrando o que afirma Ingold (2015), que o ambiente nunca é o mesmo de um momento para o outro. Assim, ao mesmo tempo em que percebemos toda a importância das ligações afetivas entre as pessoas e o lugares, também incorporamos a ideia de novas apropriações dos espaços, possibilitando a atribuição de novos valores, afetos, significados e experiências.

A experiência, segundo Tuan (2013), é entendida enquanto as diferentes maneiras pelas quais as pessoas conhecem e constroem a realidade, implicando na capacidade de aprender a partir da própria vivência. Porém, não podemos deixar de considerar a experiência enquanto algo dinâmico, que vai se reconfigurando a partir de novas vivências e de realidades que se transformam constantemente. Thrift (2008) argumenta que não existe uma experiência humana estável, sobretudo porque os sentidos podem variar, radicalmente, nas diferentes culturas e, ainda, porque o humano, através de seu todo sensorial, está constantemente sendo reinventado à medida que o corpo adiciona novos estímulos para si.

Nesta pesquisa, entendemos o corpo enquanto o local de imersão no mundo. MerleauPonty (1999, p. 605), na obra Fenomenologia da Percepção, constrói o conceito de sujeito encarnado ao entender o corpo coexistindo com as coisas e no espaço. Para ele, o sujeito encarnado "é um campo de presença — presença a si, presença a outrem e ao mundo - e porque esta presença o lança no mundo natural e cultural a partir do qual ele se compreende". Posteriormente, no livro, O Visível e o Invisível, ele usa a expressão carne do mundo, para frisar de maneira ainda mais visceral o entrelaçamento do corpo ao mundo, expressando que "meu corpo é feito da mesma carne que o mundo" (2014, p. 225). O autor nos traz a compreensão de que a relação com o ambiente se dá através do corpo com todos os seus sentidos e considera que "a experiência de minha carne como ganga de minha percepção ensinou-me que a percepção não nasce em qualquer lugar, mas emerge no recesso de um corpo" (MERLEAU-PONTY, 2014, p. 21).

Ingold $(2015)^{5}$ descreve que a percepção não é a realização de uma mente em um corpo, e sim de um organismo inteiro. No mesmo sentido, Pink (2009) argumenta sobre a indistinção da sensação e reflexão, afirmando que a separação de corpo para o fazer e da mente para o conhecer implica na objetivação da experiência corporal pela racionalização. Segundo a autora, a noção do corpo encarnado resolve essa dicotomia, em alguma extensão, para que se possa

\footnotetext{
${ }^{4}$ Essa é uma discussão que acompanha inicialmente a geografia humana e envolve outros autores, entre os quais se destaca Edward Ralph em sua obra Place and placelessness. A discussão não se finda, no sentido de que autores da pós-modernidade de outras áreas, como Tim Ingold e Nigel Thrift utilizados nesse artigo, trazem a questão do movimento para a vida, que implica em impermanência e fluidez, inclusive dos espaços. Thrift inclusive incorpora o termo espaço-movimento. Porém, optamos em manter a denominação de lugar no sentido de o demarcarmos enquanto um espaço com vínculo afetivo.

${ }^{5}$ Ingold se fundamenta em GIBSON, J. J. The ecological approach to visual perception. Boston, MA: Houghton Mifflin, 1979.
} 
entender o corpo não simplesmente como uma fonte de experiências e atividades que possam ser racionalizadas e controladas pela mente, mas como uma fonte de conhecimento e agência.

Podemos entender esse sentido de agência em Ingold (2010), dentro do que ele denomina como educação da atenção. Ele considera o sujeito ativo na captação do mundo e sua cognição em tempo real, dentro de contextos ambientais específicos em que as pessoas incorporam suas percepções e ações no desenvolvolvimento de seus conhecimentos.

Murris (2017), também, destaca essa agência também nas crianças, criticando a postura de considerá-las como uma extensão do pai ou da mãe ou como uma pessoa que vai vir a ser, como se fosse um adulto inacabado. Esse autor destaca que somos todos seres inacabados, independentemente da idade.

Dessa maneira, concebemos que os seres humanos adultos são a integridade de um corpo sensório e imerso no mundo desde a infância e que é, no agora, tanto o presente vivo em constante transformação, como um passado registrado corporalmente através dos estímulos e das experiências vividas. Conforme expõem Steil e Carvalho (2014, p. 163) "nosso modo de habitar o planeta não está separado do nosso modo de conhecê-lo". Para Tuan (2013) as categorias perceptivas do adulto são repletas de emoções que procedem das primeiras experiências na vida. E, Merleau-Ponty (1999, p. 24), considera que "a criança compreende muito além do que sabe dizer, responde muito além do que poderia definir".

De forma que é possível pensar sobre o papel da infância no estabelecimento dos valores e no modo de nos relacionarmos no mundo. Se, quando crianças, somos um corpo pulsante descobrindo a vida através de todos os nossos sentidos, é interessante refletirmos sobre como isso nos move e se soma com as novas experiências da vida adulta, e como nossas percepções de mundo foram se constituindo e se constituem diante de nossas histórias pessoais. Tuan (2012, p. 15) descreve que as atitudes e os valores nos auxiliam no conhecimento sobre nós mesmos, e afirma que "sem a autocompreensão não podemos esperar por soluções duradouras para os problemas ambientais que, fundamentalmente, são problemas humanos".

Por fim, acreditamos que exista a necessidade de um maior desenvolvimento da educação ambiental urbana, concordamos com Russ e Krasny (2015) que argumentam que essa necessidade contribui tanto para o bem-estar humano, como para a integridade ambiental em cidades. Os autores consideram que as cidades são meios complexos onde os problemas socioambientais se concentram, ao mesmo tempo que geram oportunidades de reflexões, desenvolvimento de tecnologias e aprendizado.

A partir dos pressupostos descritos até então, constituiu-se objetivo deste trabalho desvelar, desde as memórias da infância das pessoas participantes, os caminhos que as/os constituíram/constituem enquanto seres, a partir de suas relações com a natureza, e melhor compreender como as áreas verdes urbanas na cidade de Salvador fizeram e fazem parte de suas histórias. Para tanto, procuramos revisitar, através do corpo imerso e do corpo relacional no mundo, suas relações com os lugares afetivos eleitos por cada uma delas, procurando proporcionar uma experiência que também pudesse oportunizar autoconhecimento e produzir novos aprendizados, afetos, significados e percepções.

\section{Desenvolvimento da Pesquisa}

\subsection{Grupo participante}

A presente pesquisa compõe o doutoramento da primeira autora e foi realizada com nove estudantes da Universidade Federal da Bahia (UFBA) que cursaram uma disciplina, na modalidade de Ação Curricular em Comunidade e em Sociedade $\left(\right.$ ACCS $^{6}$ ), denominada

\footnotetext{
${ }^{6}$ Sobre ACCS consulte o link: https://proext.ufba.br/accs
} 
Construção de trilha interpretativa e formação de monitores em uma abordagem educativa em áreas verdes urbanas, que foi ministrada pela respectiva autora, no primeiro semestre de 2016. A turma foi composta por sete estudantes de graduação dos cursos de Ciências Biológicas e dois do Bacharelado Interdisciplinar da área de saúde ${ }^{7}$. A escolha pela disciplina, que é optativa, já indicava, previamente, que seriam pessoas com afinidade às questões ambientais, o que pôde ser confirmado ao ouvir as/os participantes no primeiro encontro sobre a intenção e expectativa em relação à disciplina.

A convivência entre a professora e pesquisadora de doutorado e as/os estudantes durante o semestre corrente da disciplina foi fundamental para a criação de vínculos. Seguimos a perspectiva fenomenológica de aprofundar a relação com as pessoas parceiras desta pesquisa, o que implica que o trabalho se realize muito mais pautado na profundidade da relação, do fenômeno e dos sentidos atribuídos, do que na quantidade de entrevistadas/os. Essa proximidade foi, inclusive, facilitada pelo número pequeno de alunas/os e pelas atividades em campo no decorrer das aulas, o que contribuiu para que as entrevistas realizadas, posteriormente, acontecessem em um clima amistoso e de mútua confiança.

\section{2 Coleta de dados}

Os dados foram coletados a partir da técnica conhecida como walking ethnography (etnografia em movimento). Iared e Oliveira (2017b) observam como os novos movimentos nas ciências humanas vêm ganhando espaço em algumas áreas, incluindo a educação ambiental. Isso acaba por refletir, também, em novas abordagens metodológicas. As autoras argumentam a favor de metodologias que captem melhor as dimensões sensoriais, afetivas e a multissensorialidade das experiências humanas, e elucidam que:

A técnica do walking ethnography considera a perspectiva de imersão do/a pesquisador/a dentro do evento do estudo, sendo que a ideia de "influenciar" o contexto de pesquisa é contestada, assumindo pesquisador/a e pesquisadas/os como participantes da investigação. Nesse sentido, mais do que observar / descrever, a experiência é vivenciada e testemunhada por todas/os as/os envolvidas/os " (IARED; OLIVEIRA, 2017b, p. 104).

Também na defesa por novas metodologias, Pink (2009) sugere que a etnografia tradicional não foi formulada para captar dados sensoriais e é insuficiente para um conhecimento mais abrangente da vida sensória das pessoas, de suas experiências e de seus valores. Em contraposição, a autora sugere a realização de uma etnografia sensorial como forma de possibilitar a emergência de dados mais subjetivos. A autora afirma que, durante o movimento, outros sentidos, além da visão, são trazidos enquanto experimentamos o ambiente, de forma que podemos melhor explorar a relação com o meio nas diferentes modalidades sensoriais. A experiência, o conhecimento e o lugar do corpo são essenciais dentro do que se denomina como etnografia sensorial, sendo a caminhada uma das formas de promovê-la. Ela ainda nos lembra sobre a necessidade de atenção para melhor interpretar a experiência dentro de determinadas culturas, que são permeadas de moralidades e convenções (PINK, 2009).

Outros autores também argumentam sobre a importância da mobilidade para melhor entender a vida das pessoas e dos demais seres vivos , bem como a ocupação ou transição pelos espaços. Dessa forma, Tuan (2013) expressa que o espaço só é experenciado se existe lugar para o movimento. Merleau-Ponty (1999) argumenta que o movimento é gerador de espaço, e que a intencionalidade do movimento corporal traz mais percepção do mundo. Thrift (2008) é enfático ao expressar que a vida humana se baseia no movimento e que é nele que se capta seu fluxo anímico. Para Evans e Jons (2010) o andar é considerado uma forma de se envolver com

\footnotetext{
${ }^{7}$ Esse curso também possibilita a entrada para outros cursos de graduação da UFBA. Entre as duas pessoas inscritas desse bacharelado, um aluno objetiva cursar ciências biológicas e outra aluna, medicina.
} 
a paisagem. E, Ingold (2015, p. 38) argumenta, também, que o nosso habitar e as descobertas do mundo ocorrem em movimento. Para esse autor "o caminho, e não o lugar, é a condição primordial do ser, ou melhor, do tornar-se" e o movimento é o modo fundamental pelo qual os seres vivos habitam a Terra.

Através desses argumentos, consideramos que o movimento associado à entrevista nos traria uma percepção mais apurada das relações entre as pessoas e os lugares, se comparada às entrevistas convencionais, pois, conforme expõem Iared e Oliveira (2017a):

Ao pesquisar a afetividade e o sensível, é necessário aplicar metodologias mais coerentes com essa dimensão da experiência humana. Particularmente, acreditamos que uma das tarefas da pesquisa em educação ambiental está em como interpretar e representar, para além das relações humanas, a "materialidade da experiência" (IARED; OLIVEIRA, 2017a, p. 4).

Dentre as possibilidades de emprego da walking etnography, utilizamos enquanto metodologia a walking interview, que traduzimos livremente como entrevista em movimento. Entrevistar as pessoas em movimento, e em lugares significativos para elas, possibilita a emergência de dados mais significativos, pois através do engajamento com a paisagem é possível acessar atitudes, conhecimento, conexões e sentimentos sobre o meio envolvente.

Solicitamos, então, que as pessoas participantes escolhessem uma área verde em Salvador, a qual frequentavam ou com a qual mantinham algum vínculo afetivo. Também, propusemos que realizássemos, conjuntamente, alguma atividade que costumavam praticar naquele lugar. Assim, cada uma das entrevistas aconteceu em um lugar da cidade, com a realização da atividade proposta pela pessoa participante.

O encontro foi todo gravado em áudio, e a transcrição foi feita com ênfase nos trechos específicos de interesse para o recorte proposto neste artigo. Além disso, solicitamos que após a entrevista fosse feito um relato do que fora vivido, naquele momento, em relação a novas reflexões e sentimentos mobilizados. A primeira autora, que realizou as atividades, também fez esse relato e ambos foram trocados individualmente, com todas as pessoas participantes, por email.

A entrevista seguiu um roteiro semiestruturado, respeitando o tempo da vivência em cada espaço, dos respiros, da contemplação e das intercorrências, já que estávamos no ritmo da cidade. Respeitamos, também, o fluxo dos temas diversos que surgiram motivados pela paisagem, por algo que acontecia em determinado momento. Alguns dos assuntos previstos, muitas vezes, acabaram por emergir naturalmente em algum ponto da conversa. Porém, todas as entrevistas se iniciaram com a solicitação de que contassem sobre sua infância em relação ao convívio com a natureza e se realizavam programações em ambientes naturais ou em áreas verdes urbanas.

Nos resultados, apresentamos qual o lugar e a atividade que cada pessoa escolheu e o que percebemos de relevante em relação às memórias de infância na constituição dos vínculos com o ambiente, bem como o que foi gerado em relação ao autoconhecimento, seja ao revisitar essas memórias, seja a partir de alguma pergunta que proporcionou novas reflexões. A perspectiva da primeira autora é apresentada, através de dados gerados na escuta e transcrição do áudio gravado durante a walking interview e pelo seu relato realizado logo após a caminhada.

Posteriormente, apresentamos a perspectiva das pessoas entrevistadas através dos relatos realizados por elas. Optamos em apresentar os dados, pautadas na fenomenologia, dando voz a todas as pessoas que participaram e considerando todas igualmente importantes. Ressaltamos que obtivemos a autorização das pessoas participantes para utilização e divulgação dos $\operatorname{dados}^{8}$, bem como a utilização dos nomes verdadeiros, pois não considerarmos que existam

\footnotetext{
${ }^{8}$ A pesquisa foi aprovada no Comitê de Ética da plataforma Brasil.
} 
dados que os/as exponham negativamente e postulamos uma perspectiva de humanizar as pesquisas, dando-lhes uma aproximação mais próxima da vida. Um outro resultado, não almejado, que surgiu espontaneamente através desses relatos, foi um retorno do que esse tipo de entrevista proporcionou às pessoas envolvidas.

Observamos que muito do processo de autoconhecimento se revelou no momento posterior à entrevista, quando refletiram e escreveram sobre seus sentimentos. Consideramos que esse momento de pensar e escrever sobre a experiência é fundamental para que ela se consolide. Nesse sentido, Iared e Oliveira (2017a), destacam a importância do momento posterior da vivência para que a reflexão transcenda a entrevista, pois, dificilmente, no tempo da entrevista, é possível elencar todas as ideias, memórias, opiniões e percepções.

\section{Apresentação dos Resultados}

O encontro com Sandra foi na orla marítima, no bairro de Itapuã. A entrevista aconteceu enquanto caminhávamos, uma atividade comumente praticada por ela naquele espaço tão significativo em sua vida, pois ela afirma que suas caminhadas na orla a auxiliaram na cura de um processo de depressão. Sandra nasceu e foi criada no Pará, e reside há sete anos em Salvador, onde estabeleceu uma profunda conexão com o mar. Na infância destaca seu quintal como o responsável pelo estabelecimento de um vínculo com a natureza e, em especial, um jambeiro, no qual subia, brincava, que tinha balanço e que cobria o chão de flores cor de rosa.

Quando perguntei sobre os rios, sim, os rios eram muito especiais, principalmente os igarapés de água fresca. Seu campus universitário também estava localizado em frente a um rio, o qual afirma ser fonte de contemplação, explicando, porém, que só os destemidos entravam, pois tinha muita correnteza. Sua mãe também criava animais para o abate. E, do mesmo modo que tinham afeição por eles, também foram ensinados, desde cedo, que um dia eles seriam destinados ao consumo. Sandra me relata, porém, que "às vezes era estranho olhar pra uma coxa e lembrar do bicho".

Em outro momento da entrevista, quando a participante foi questionada sobre as diferenças entre vivenciar a natureza no espaço urbano ou fora dele, Sandra começou respondendo que não é em qualquer lugar de natureza que gosta de estar. Que no Pará ela ia muito para a mata, mas aqui no estado da Bahia, como na Chapada Diamantina, por exemplo, não gostou de estar. Após um breve silêncio, ela diz que foi uma boa pergunta, porque permitiu a ela refletir sobre isso e, com mais um pouco de conversa/reflexão, percebeu que o problema das trilhas na chapada é o excesso de sol, pois não há sombra como nas florestas do Pará e, na verdade, ela não gosta e não se sente bem com excesso de calor (até foi esse o motivo para marcarmos a caminhada da entrevista bem cedo). Dessa forma, a pergunta permitiu que Sandra conhecesse melhor seus limites e motivações. No relato após a entrevista, Sandra escreveu que:

\footnotetext{
A entrevista superou as minhas expectativas, pois configurou para mim, uma experiência de descoberta e autoconhecimento. Pude recordar remotos cenários mentais há muito tempo guardados em minha memória. E, nesta oportunidade, pude fazer uma releitura desse passado e minha relação com a natureza. Pude perceber então, nesta curta hora, que há muito mais em mim da natureza vivenciada na infância e juventude do que eu poderia imaginar (HOFSTATTER, 2018. p. 138. Grifos das autoras).
}

Com Helione, o encontro aconteceu na Ponta de Humaitá, na cidade baixa. É um lugar turístico, de extrema beleza cênica. Helione optou por me apresentar na região os espaços mais significados em sua memória, devido aos momentos de infância que ali vivenciara. Assim, caminhamos durante uma parte da entrevista e sentamos para contemplar o mar, como ela costumente fazia, no Forte de Nossa Senhora de Mont Serrat, pois ali é o ponto mais alto do lugar e possui uma vista privilegiada da praia de Boa Viagem. Helione foi criada em Salvador 
e passou a infância bem próxima ao mar, pelo qual desenvolveu um enorme vínculo afetivo e sentido de vida. Durante a entrevista, ela foi relembrando suas escolhas de vida, como a profissão, e me conta que agora busca proporcionar às crianças da família as mesmas vivências junto à natureza que lhe foram proporcionadas. Em seu relato, Helione afirma que:

A entrevista proporcionou uma sensação maravilhosa de recordação da minha
infância e adolescência, as quais vivenciei em total contato com áreas naturais. Na
infância, graças aos meus pais e avós, que sempre me proporcionaram passeios em
que a natureza estivesse presente. Na adolescência, através do amor pela natureza que
já morava em mim, que já direcionava meus caminhos. A conversa foi bastante fluida,
e despertou ainda mais minha conexão com a mãe natureza, permitindo que a
energização, a qual me referi em uma das respostas, ocorresse de forma tranquila e
espontânea, apesar do Sol a pino. Recordar momentos felizes e de bastante
aprendizado me fez querer (ainda mais) multiplicar esses sentimentos para as pessoas,
principalmente às crianças e aos adolescentes, que são potenciais multiplicadores
aqui, no presente, e no inesperado futuro. Estar ali reavivando memórias marcantes
e que, consequentemente, me fizeram traçar o caminho profissional que escolhi para
a minha vida, me fez perceber que a trilha a percorrer a partir de então, seja no ensino
sobre a natureza ou no exercício como Bióloga, é uma escalada, e provavelmente
árdua. Porém, a vista parece ser linda! (HOFSTATTER, 2018. p. 138. Grifos das
autoras).

Poline escolheu a praça do Campo Grande, no centro da cidade, pelo fato de ter sido criada naqueles arredores e ali ser um caminho habitual, de ônibus ou a pé. Poline também optou pela caminhada enquanto atividade. Assim, o primeiro momento da entrevista ocorreu em um banco de praça e, depois, fomos caminhando por ela, observando novos detalhes no fluir da conversa. As árvores da praça sempre chamaram muito a sua atenção. Ela passou a maior parte da infância em Salvador e seu contato com a natureza acontecia, principalmente, quando estava na casa da tia no interior do estado. No quintal da tia brincava com os bichos que eram criados, como a galinha, o porco, a vaca. E, por meio disso, desenvolveu um forte elo com os animais não humanos, que ganharam dela nome e afeto.

Poline tornou-se vegana na idade adulta e possui um censo ético admirável em relação a todos os demais elos da natureza. Ao ser solicitada que diferenciasse a natureza urbana da natureza afastada dos centros urbanos revelou um aspecto muito interessante: que apesar de sentir uma maior imersão na natureza longe da cidade, pela possibilidade de um contato mais abrangente, corporal e intenso, ela afirma que essa natureza não lhe promove lembranças, pois não tem nenhuma conexão com seu passado. Enquanto que passar por uma rua arborizada, na cidade em que foi criada, lembra seus lugares da infância e possibilita que reviva memórias afetivas de vinte anos atrás. Ao término da entrevista, Poline relatou que, ao responder as perguntas, pôde reviver alguns momentos da infância e que, quando verbalizamos e organizamos as ideias, nossas conexões com a natureza são fortalecidas e ficam mais enraizadas. Ela descreve que:

A visita ao Campo Grande se iniciou com uma espécie de retrospectiva sobre minha vida, já que os motivos que me levam a gostar desse lugar e de outras áreas verdes me fazem relembrar de aspectos da minha primeira infância, alguns dos quais não são muito agradáveis, outros, no entanto, me trazem uma sensação boa de momentos divertidos e de quando tive os primeiros contatos com a natureza e passei a gostar bastante de animais. Relembrar esses momentos na entrevista funcionou como uma forma de autoconhecimento, porque dessa forma esses pensamentos se organizaram na minha mente para que pudessem ser relatados da forma mais clara possível (...). Entrar no assunto do caminhar por matas também nos levou a reflexões sobre a forma como nós, humanos, sentimos nosso corpo nessas situações de desafios, em que o próprio equilíbrio é posto à prova em lugares mais íngremes (HOFSTATTER, 2018. p. 139. Grifos das autoras). 
Carine reside há pouco tempo na cidade de Salvador. E o local que mais frequenta é o campus da UFBA (Universidade Federal da Bahia), no bairro de Ondina. Dessa forma, esse foi o espaço que ela elegeu para nos encontrarmos, porém fizemos uma atividade diferente das habituais, jogamos peteca, que é uma atividade que ela gosta de realizar em áreas verdes, mas ainda não tinha realizado na UFBA. Carine foi criada em Inácio Martins, uma cidade muito pequena, totalmente arrodeada de floresta e a de maior altitude no Paraná. Seu pai sempre organizava programações junto à natureza. Assim, seu contato foi intrínseco com as matas, com as cachoeiras da região, no sítio do seu avô. Faziam acampamentos em família e considera que teve muita sorte de ter esse contato desde sempre.

Ela nos revelou que um dos temores, quando se mudou para Salvador, seria a falta de árvores, mas quando entrou na UFBA e descobriu aquela mata, mesmo que pequena, sentiu um enorme alívio. Percebemos, então, o quão afetivo é seu vínculo com esses outros seres não humanos e a dimensão do conforto que lhe proporcionam a cada dia que ela está longe de sua terra natal e de seus outros elos. É como se ela pudesse reviver um pouco da sua infância na mata, desse lugar de carinho na vida. Sobre a entrevista, Carine descreveu que:

Me fez refletir sobre o porquê de gostar tanto de estar "no mato" e me fez reviver
cenas e situações que há muito não lembrava, da infância procurando por pedras de
"giz" pra pintar amarelinha na calçada; das viagens entre a mata densa para ir à cidade
mais próxima; das pescarias e cachoeiras (HOFSTATTER, 2018. p. 140. Grifos das
autoras).

O encontro com Rodolfo se deu no Parque de Pituaçu, um parque urbano com uma área considerável de reserva de Mata Atlântica e lagoas naturais, muito frequentado pelos moradores de Salvador. Ele o escolheu, pois conhece o local desde criança, quando vinha à Salvador, além de ser um lugar onde ele já realizou pesquisas e onde também gosta de realizar passeios ao ar livre. Rodolfo, optou pelo passeio livre no parque, assim como fazia com a família. Dessa forma, caminhamos um pouco pela área do parque, até acharmos um canto convidativo para nos sentarmos em frente à lagoa, embaixo de uma árvore, em pedras que mais pareciam poltronas e, ali, continuamos nossa conversa.

Rodolfo passou boa parte da infância no município de Valença, mas mudou muitas vezes de cidade, por causa da sua mãe que era frequentemente transferida pelo trabalho. Entretanto, sempre morou em casa com quintais e narrou que sua vivência, na infância, junto aos quintais, proporcionou a constituição de sua conexão com a natureza no espaço urbano. Afirmou que até hoje, enquanto adulto, consegue manter muito bem seu elo com a natureza na cidade ou em curtos intervalos. Citou, como exemplo, que gosta de se sentar no gramado, entre as aulas na universidade para relaxar um pouco. Dessa maneira, não sente muita diferença entre as relações com a natureza urbana ou uma mais silvestre, dizendo que: "a qualidade não vejo muita diferença não. Até porque a vida toda o contato que tive com a natureza foi urbana. Se eu não conseguisse me conectar com a natureza urbana, eu seria um desconectado (risos). Desde criança as áreas verdes que frequento são as urbanas". Rodolfo também conviveu com a praia desde cedo e afirma que a relação com o mar envolve toda a família. Em seu relato após a entrevista explicou:

Tive a oportunidade de refletir sobre diversas questões pessoais que pouco tenho tido disposição para refletir ou recapitular os fatos de forma ordenada (...). Acredito que expus o máximo sobre minha relação com a natureza e como ela foi construída dentro dos aspectos de minha formação como pessoa, desde a infância com a colaboração de parentes e momentos marcantes nos quais as áreas verdes urbanas me marcaram pessoalmente. Uma reflexão que chamou a minha atenção foi o fato de eu não distinguir muito o lazer que posso obter em uma área verde urbana ou não-urbana e como isso foi construído ( HOFSTATTER, 2018. p. 140. Grifos das autoras) 
Uésclei escolheu o zoológico de Salvador para o encontro, devido ao amor e admiração que sente pelos animais, um espaço que frequenta sempre que pode para observar e entrar em contato com eles. Assim, praticamos o que Uésclei constuma fazer no zoológico, que é a visita aos recintos dos animais. Fomos caminhamos e conversando sobre sua vida e fazíamos pausas para observar e comentar algo sobre os animais que tanto admirava.

Ele nasceu no município de Santo Amaro, mas foi criado em São Francisco do Conde, onde vive até hoje, ambas cidades localizadas no recôncavo baiano. E, mesmo estudando na UFBA, em Salvador, não deixou sua casa e viaja uma hora e meia, todos os dias, para, além de estudar, realizar seus sonhos. Ele foi um menino criado no quintal, que pegou o gosto pelas plantas, pelo cultivo, pelo cuidado aos animais e pela simplicidade de ser e sente-se inconformado diante de toda e qualquer violência humana para com os demais animais. Contou que, desde criança, pedia às pessoas que não os maltratassem e narrou a dificuldade que enfrenta em sua localidade de abordar as pessoas sobre temas como caça e pesca indiscriminada, pois sua fala, nesse sentido, pode ganhar uma conotação de superioridade pelo fato dele cursar uma universidade. Uésclei descreveu que, muitas vezes, sente desesperança em relação aos humanos, o que interpretamos como um sentimento profundo em querer que os animais não humanos sejam tratados com mais respeito e igualdade. Após a entrevista, ele refletiu que:

\begin{abstract}
No início da conversa a professora me questionou, em que momento da minha infância comecei a me interessar pelas questões relacionadas à preservação do meio ambiente. Tive o privilégio de passar a minha pré-adolescência em um ambiente em que o verde estava por toda parte. O sítio de meus avós era o lugar onde costumava passar minhas férias de verão, assim que acabava as aulas corria para lá. Aquele ambiente rodeado de vida fazia me sentir muito bem, lembro nitidamente dos momentos, ora de lazer, ora de frustração, ao lado dos meus primos... O fato é que na maioria das vezes sempre que podia subia em um pé de árvore para admirar lá do alto todo o ambiente ao redor. Pode-se dizer que foi nesse período em que começou a me despertar para o cuidado com o meio ambiente, em especial os animais (HOFSTATTER, 2018. p. 141. Grifos das autoras).
\end{abstract}

Rafael nasceu e foi criado em Salvador e escolheu uma Reserva Particular de Patrimônio Natural - RPPN, o Vale Encantado, como espaço para o nosso encontro de observação de aves. Esta é a maior área de mata atlântica da cidade de Salvador e também possui lagoas naturais. O acesso é restrito, via condomínio fechado, mas como Rafael é voluntário da reserva e a frequenta comumente, não tem restrição. Aproveitando as primeiras horas do dia, o horário dos pássaros, a primeira autora imergiu no mundo de Rafael para compreender esse amor que nutre pela atividade. O seu pai é o fundador do clube de observação de aves da Bahia, então, segundo ele, é uma ligação que começou em sua vida uterina. A observação de aves é seu labor, lazer, hobby, paixão e constitui forte elos familiares e de amizade, é toda uma vida direcionada para isso. Ainda não tínhamos conhecido alguém que tivesse uma atividade na natureza tão profunda na vida como é para ele. Em seu relato, após a entrevista, assinalou que:

\footnotetext{
Vejo as trilhas como refúgio fundamental do ritmo de vida em que vivo. Ver a próxima espécie de ave é o que me faz viajar pra conhecer novas cidades e biomas, me traz amigos, além de ser um momento legal de convivência com minha família. (...) fiquei emocionado por fazer a reflexão do quanto as aves são importantes pra mim (HOFSTATTER, 2018. p. 142. Grifos das autoras).
}

Juliana escolheu uma praça central, chamada Passeio Público, para realizarmos nossa entrevista. É uma praça linda, cheia de árvores centenárias, que já foi o quintal do palacete onde residiam os governadores da Bahia, no século XIX. Juliana passou ali muitos momentos de sua 
adolescência, e por isso a escolheu. Usava o local para se reunir com um grupo amigo, para estudar e contemplar o pôr do sol. Assim, nossa atividade seguiu um pouco do que ela realizava ali, sentamos um pouco nos bancos em que ela costumava sentar com amigas/os para conversar e, depois, fomos para o ponto de vista privilegiado em que ela gosta de observar o sol poente.

Sua infância foi no recôncavo baiano, em Santo Antônio, onde teve muito contato com as roças familiares. No verão ia com a família toda passar o mês na Ilha de Itaparica, momentos em que se inicia sua relação com o mar, uma relação tão forte que, em certo momento da entrevista, relatou que: “quando estou no mar, sou mar". Ela mantém, até os dias de hoje, uma conexão e uma entrega muito grande junto a qualquer outra forma de natureza e expõs que:

\begin{abstract}
Conversamos sobre o passado, o presente e o futuro num diálogo leve e tranquilo. Relembramos histórias da infância, dos sabores das brincadeiras de criança nas praças, jardins e praia. O contato mais íntimo com a natureza: o ser natureza! Sentirse árvore, pensar como um pássaro, respirar ar leve como uma folha. Conversamos sobre sentimento, sobre o que se tem por dentro e só mostramos a ponta da complexidade do ser. Entramos em conexão e a cada minuto éramos tomadas pelo espírito da natureza. Quanta beleza num só lugar (HOFSTATTER, 2018. p. 143. Grifos das autoras).
\end{abstract}

Esaú nasceu e foi criado em Salvador, e diz que desde pequeno amava o zoológico e pedia para o levarem até lá e, por isso, também escolheu esse espaço. Assim que ele pôde, após entrar no curso de biologia, foi procurar estágio ali, alegando para a escolha sua paixão pelos animais e por aquele lugar. Quando deu certo, ele relata que estava vivendo um sonho. Estagiou dois anos no zoológico, passando por diversos setores, de forma que vivenciou esse espaço de maneira intensa e multi-experiencial. Assim, Esaú optou em caminhar pelo zoológico, apresentando à primeira autora cada um dos animais que vive naquele espaço, pois conhece todos pelo nome e nutre uma enorme afeição por eles.

Em meio às histórias de cada um dos bichos, a de Esaú também foi se revelando. Quando criança também amava o sítio, a terra, a mata e narrou que sua família também sempre gostou do contato com a natureza. Em um momento da caminhada, chegamos ao local onde ele e sua família faziam piqueniques e, ao mostrá-lo, refletiu o quanto parecia maior quando era criança. Essa outra percepção de espaço durante infância realmente é, de fato, muito comum. Esaú, após a entrevista, relatou que: "viver a natureza, não só no Zoo, me faz sentir em paz (em casa). A energia presente nela, e toda a simplicidade que ela carrega, me faz dependente dessa tamanha lindeza” (HOFSTATTER, 2018. p. 179. Grifos das autoras).

\title{
4. Discussão de Resultados
}

Como indicado na coleta de dados, os resultados refletem tanto as memórias reelaboradas de infância na constituição dos vínculos com o ambiente, como o que foi gerado em relação ao autoconhecimento. Discutiremos, ainda, o que a walking interview significou às pessoas envolvidas.

Primeiramente, é possível observar que perguntas simples sobre as trajetórias de vida, feitas em momentos oportunos e quando há abertura para a entrega e o diálogo, podem contribuir com os processos de memória e de autoconhecimento. Observamos que educação ambiental praticada em lugares abertos, com o movimento do corpo, certamente contribui para que as lembranças venham no fluir da interação entre corpo/ambiente, o que também é descrito por Horton et al. (2014) e Iared (2015). Percebemos, através dos relatos enviados por cada pessoa, trechos em que descrevem esses elos de suas lembranças e as formas como perceberam que suas vivências de infância, na maioria das vezes, se incorporam as suas atuais escolhas. 
Pudemos evidenciar o quanto a natureza urbana proporciona diferentes experiência para cada pessoa. Na entrevista de Esaú, por exemplo, o momento em que estávamos no local que aconteciam os piqueniques ele pode reviver a dimensão que aquele lugar tinha em sua infância e no agora. Com Sandra, foi extremamente tocante reviver, com ela, uma atividade que lhe trouxe a cura de um processo tão profundo. Na entrevista com Poline, quando ela olha as mesmas árvores e a paisagem que vê quase cotidianamente, de outra forma, reflete sobre o bemestar que sente nesse olhar, o que não seria possível se a entrevista tivesse acontecido em qualquer outro local. Ela também traz uma dimensão muito importante de entendimento e engajamento no mundo ao afirmar que sua lembrança faz com que sua ligação com o ambiente fique ainda mais forte. A experiência que a primeira pesquisadora teve com Rafael, na imersão da observação das aves, nos fez compreender, de maneira muito mais visceral, o amor que Rafael mantém pelas aves. Nesse tipo de imersão, inclusive, nem sempre as palavras são necessárias, pois as percepções são tão pulsantes que suprem a expressão oral. Esses dados evidenciam o que Pink (2009) argumenta sobre a multissesorialidade no ato da pesquisa para captar um conhecimento mais abrangente da vida sensorial das pessoas.

Também pudemos refletir, pelos encontros e relatos, que as pessoas adultas de hoje foram crianças que estabeleceram vínculos com a natureza precocemente, pela convivência, o que pode ser analisado retomando a ótica de Merleau-Ponty (2014) de que a criança compreende muito mais do que é capaz de dizer, e de Tuan (2013), ao considerar que as categorias perceptivas do adulto são influenciadas pelo experenciado na infância. Porém, cabe ressaltar que não consideramos apenas a necessidade desses vínculos nas crianças para as pessoas adultas que viriam a ser, pois como descrevem Murris (2017) e Ingold (2010) a educação da atenção nos traz elementos de reflexão sobre a agência do ser em cada etapa de vida, em cada contexto específico e nas relações contínuas no mundo (THRIFT, 2008).

Para Ingold (2015), vivemos um emaranhado de relações entre espaços, humanos e não humanos na tessitura de uma vida em malha, que o autor denomina de meshwork. Essa ideia é contemplada por Carvalho e Steil (2012, p. 240) que nos lembram que o conhecimento não se processa "dentro de um sacrário mental interior, protegido das múltiplas esferas da vida prática, mas em um mundo real de pessoas, objetos e relacionamentos".

Oliveira (2004, p. 19) anuncia que "desde o nascimento, as funções sensórias, corporais e mentais devem ser trabalhadas no espaço para que sejam adequadamente desenvolvidas e aprimoradas. A criança é um todo, onde estas funções interligadas e interdependentes atuam no seu desenvolvimento". É evidente o quanto as crianças necessitam de espaço e do movimento para um melhor desenvolvimento em relação às experiências sensórias e apuração dos sentidos.

O que foi vivido em cada uma dessas infâncias descritas, tem seu valor intrínseco e situações específicas. Porém, como as entrevistas ocorreram com as pessoas já adultas, é através de suas memórias que procuramos conhecer um pouco de como essas infâncias se incorporam ao que vivem e são, hoje, de forma a "repensar o próprio humano através da criança" (MURRIS, 2017, p. 185). O fato, por exemplo, de a maior parte das pessoas entrevistadas cursar biologia agrega em suas vidas mais conhecimento e vínculos com a natureza. Todas as pessoas entrevistadas continuam fazendo atividades em ambiente natural e tudo isso proporciona novas vivências que reforçam ou reinventam seus elos afetivos.

Dessa maneira, salientamos que a ligação com a natureza cria um engajamento no mundo que se realiza de diversas maneiras: influenciando na escolha profissional; na forma cotidiana com que as pessoas lidam com as questões ambientais; no envolvimento com instituições ambientalistas; no papel que exercem profissionalmente na magistratura etc. Isso rebate as críticas de uma postura romântica sobre a ligação afetiva entre seres humanos e demais elos do ambiente ser desconectada das questões políticas (LAYRARGUES; LIMA, 2011). O autoconhecimento é, na verdade, uma das formas para que as pessoas, a partir de uma reconexão 
com suas origens e com suas histórias de vida, possam lutar/estar nas causas socioambientais com mais propriedade, amor e identificação ao reconhecerem nelas suas profundas conexões.

Carvalho (2006) compõe o entendimento de três dimensões humanas a serem consideradas na educação ambiental, entre as quais estão a dimensão dos conhecimentos, a dimensão da participação e cidadania e a dimensão ética e estética, que se insere no campo dos valores. Todas essas dimensões estão imbricadas e constituem a dimensão política da educação ambiental. Não que exista uma divisão real, são simplesmente elencadas nessas três dimensões para serem melhor compreendidas. Porém, na prática educativa, ainda enfrentamos muita resistência em trabalhos que aprofundam suas temáticas no campo dos valores, isso porque existem alguns trabalhos de educação ambiental, nessa esfera, que são realizados de maneira descontextualizada e não reflexiva, o que contribui para gerar preconceitos, principalmente, por parte das pessoas que se inserem na educação ambiental crítica.

Entretanto, é necessário lembrar que há séculos estamos estruturando bases de pensamento e princípios de sociedade que ainda dicotomizam razão e emoção, com uma consequente valorização do que é tido como razão em detrimento do que é tido como emoção. Assim, indicamos a necessidade de ruptura com esses antigos padrões, considerando a indissociabilidade do ser em todas suas dimensões e valorizando todos os aspectos que o compõem e que estão presentes em suas relações, através de trabalhos sérios, comprometidos e contextualizados à realidade social.

Dessa maneira, reconhecemos e valorizamos a importância do posicionamento reflexivo, crítico e sócio-político e não queremos dizer que o autoconhecimento e reconhecimento dos vínculos afetivos ambientais bastam à educação ambiental em todas as suas instâncias. A nosso ver, são caminhos imprescindíveis, mas que não se findam. No contexto desta pesquisa, poderia haver uma continuidade do trabalho educativo, considerando outras vertentes. Lembrando que estamos atuando na e pela cidade, podemos pensar no fomento às diferentes formas de organização social, traçar os caminhos e as formas aos espaços de participação cidadã, criar práticas pedagógicas propícias a um melhor aproveitamento e ocupação dos espaços públicos no caminho da democratização e universalização da educação, além de estabelecer lutas civis pela manutenção, melhor distribuição ou pela criação novas áreas verdes públicas.

Sabemos que boa parte da população tem pouca oportunidade de realizar vivências com a natureza em áreas verdes urbanas, seja por falta de quem as ofereça e/ou por falta de acessibilidade a esses espaços. E, como nos lembra Oliveira (2004), esses vínculos não podem ser criados se forem vividos de maneira esporádica, por isso a necessidade de oferecer áreas verdes no espaço urbano, onde a maioria das pessoas está vivendo. Como enfatizado por Steil e Carvalho (2014, p. 164): "é impossível dissociar a mente do corpo, a cultura da natureza, o conhecimento da experiência. Para conhecer, a partir da perspectiva ecológica, é necessário estar imerso na matéria e no mundo através do engajamento contínuo no ambiente".

Além disso, constatamos em todas as entrevistas que é a natureza urbana que reside nas memórias afetivas das pessoas participantes, justamente por serem as áreas onde cresceram e que remetem aos momentos vividos com as famílias e pessoas amigas. Esses elos se fortificam no momento em que continuam frequentando esses espaços, de forma que podemos retomar o que Thrift (2008) explana sobre os novos estímulos que se incorporam constantemente ao ser.

Através da figura 1, podemos perceber as áreas verdes de Salvador enquanto lugares de constituição de sentimentos, sentidos, cura, realização, vida. Na maioria das vezes, os discursos sobre a importância das áreas verdes nas cidades se restringem aos aspectos ecológicos e ecossistêmicos, com destaque aos serviços ambientais, tais como regulação térmica, redução da poluição, potencial paisagístico, refúgio de fauna. Porém, trazemos dados sobre as possibilidades de vivências humanas e significados atribuídos a essas áreas, os quais não podem 
ser ignorados na constituição dos espaços urbanos. Além do mais, temos milhares de outros seres que dependem desses espaços para existir.

Lembramos que a distribuição das áreas verdes em Salvador é muito desigual, e que a maior parte da cidade não atinge os índices mínimos de arborização recomendados. Sendo assim, pensar em uma cidade repleta de praças, parques, canteiros, rios vivos e jardins bem distribuídos pelo espaço urbano pode ser um diferencial na formação das crianças e de toda população em relação ao desenvolvimento de habilidades e dos aspectos sensíveis humanos. Grün (2008, p. 4), também argumenta que "a questão que se coloca para a Educação Ambiental é como fazer uma reapropriação social dos lugares para podermos ter uma noção de lugar a assim engendrar práticas mais orientadas ecologicamente e mais situadas".

Figura 1 Imagem aérea de Salvador com as localizações das entrevistas e suas respectivas significações pessoais

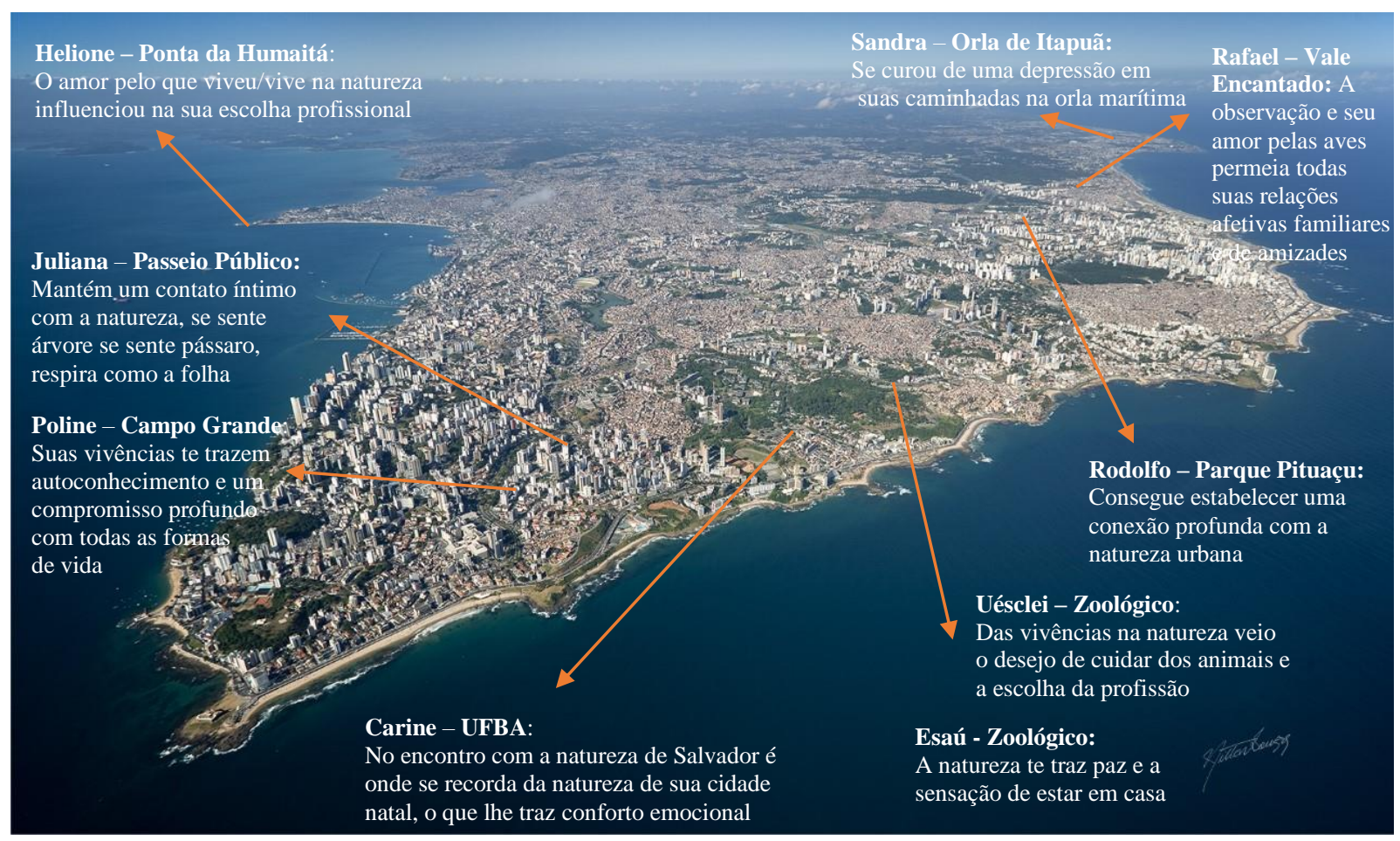

Fonte: Fotografia cedida por Nilton Souza

Vimos a importância dessas vivências ambientais em relação aos elos afetivos que trazemos vida afora. Conforme afirma Oliveira (2004, p. 25) sobre o desenvolvimento da criança: "ela necessita de espaço para conhecer o mundo, a natureza, exercitar seus movimentos, trabalhar seus sentidos, sentimentos e o tempo". Horton et al. (2014) realizaram um estudo sobre o cotidiano das caminhadas de crianças e jovens na Inglaterra e constataram o quanto essa mobilidade é importante na formação dos vínculos com a cidade e noções de espacialidade, no cultivo das relações de amizades (compartilhando histórias e brincadeiras) e identidade sociocultural, reafirmando, mais uma vez, o quanto os espaços urbanos devem ser acessíveis à elas. Nesse sentido, também podemos pensar e incentivar práticas educativas ambientais passíveis de ser realizadas em diferentes espaços abertos pela cidade, enquanto mais uma forma de apropriação do espaço urbano.

Iared (2015), a partir do conceito somaesthetics enunciado por Shusterman $(2008)^{9}$, nos traz a compreensão das ligações viscerais que mantemos, desde o nascimento, com o mundo da vida como criaturas na/com/como natureza cujos significados vêm de nossas percepções

SHUSTERMAN, R. Body consciousness: a philosophy of mindfulness and somaesthetics. Cambridge: Cambridge University Press, 2008. 
corporais, movimentos, emoções e sentimentos. Para Grün (2008, p. 8), “a apreensão dos corpos aos lugares se dá através de um estar-com que é inexorável à nossa condição no mundo da vida. Negligenciar o mundo da vida é negar a experiência do corpo-vivido".

Relembrando que a maior parte das crianças brasileiras, hoje, cresce nas cidades, um dos aspectos que deve ser considerado nos cuidados com o ambiente urbano é a adequação às necessidades das crianças e a manutenção de espaços naturais. A liberdade que as crianças tinham na cidade, principalmente nas capitais e grandes cidades, vem diminuindo por diversos fatores, o que está restringindo os espaços de circulação, experimentação e formação das crianças (OLIVEIRA, 2004).

Assim, não podemos deixar de pensar em que tipo de cidade, de ambiente, de natureza estamos sendo, vivendo e oferecendo não só às nossas crianças, mas para toda a população. Diante da importância das vivências ambientais na constituição permanente dos seres humanos, não podemos deixar de refletir, enfrentar e re(im)plantar mais vida nos espaços urbanos.

Por fim, ressaltamos o quanto a walking interview se demonstrou uma forma de coleta de dados reflexiva e sensível, que exemplificamos através de algumas frases proferidas pelos relatos das pessoas participantes (HOFSTATTER, 2018, p. 138-143):

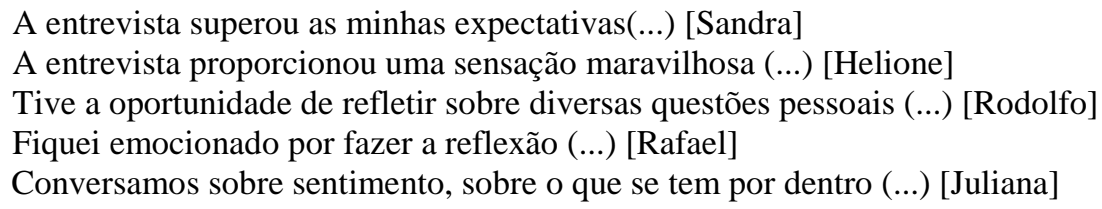

Destacamos, para além do desenvolvimento da metodologia empregada, o fato das pessoas estarem em locais afetivos, por elas escolhidos, e o fato de já haver uma relação harmoniosa, contruída anteriormente, entre a primeira autora e o grupo participante. Esses aspectos, certamente, contribuiram para que a entrevista fluísse em clima amistoso e com a confiança necessária para que as pessoas pudessem expor seus sentimentos. Contudo, pudemos perceber o quanto essa metodologia pode superar outras formas de entrevista que, muitas vezes, se demonstram maçantes ou monótonas para as/os entrevistadas/os. Entendemos que ela requer um investimento de tempo, além de ser necessário verificar se essa forma de coleta de dados responde aos objetivos pesquisados. Entretanto, não deixamos de recomendá-la às pesquisadoras e aos pesquisadores que pretendem explorar outros sentidos para além do verbal, e que visam melhor compreender as relações entre as pessoas e os lugares.

\section{Considerações Finais}

Como pudemos observar, a memória e o autoconhecimento são elementos importantes e que podem ser incluídos nas práticas educativas, pois o que é vivido na infância tem um papel relevante na formação do ser e influencia nas escolhas que as pessoas fazem em suas vidas. Neste sentido, pensar nos espaços para essa experimentação e práticas educativas apropriadas para os primeiros anos de vida pode contribuir muito para uma melhor formação ambiental de nossa sociedade. Porém, não podemos esquecer que as experiências e vivências acontecem de forma contínua e se transmutam no acúmulo de novos estímulos, pois somos seres inacabados e imersos na malha das relações com o mundo, com outros seres humanos e não humanos, de forma que os espaços e trabalhos com as pessoas adultas também não podem ser negligenciados, incluindo processos reflexivos e políticos.

Além disso, como pesquisamos as infâncias a partir de reelaborações nas pessoas já adultas, indicamos a necessidade de pesquisas a serem realizadas diretamente com as crianças, para melhor compreender suas percepções sobre a cidade, o ambiente, a natureza, apropriações 
dos espaços públicos. Assim, são questões que podem ser aprofundadas em trabalhos futuros em relação à diversidade das formas com que podem ser utilizadas.

Esta pesquisa se insere em uma abordagem da educação ambiental que considera os novos materialismos e a agência dos seres não humanos na constituição de uma vida em movimento. Assim sendo, consideramos que a walking interview possibilitou uma captação mais sensível dos sentidos humanos das pessoas envolvidas e melhor elucidação dos vínculos entre as pessoas e os demais elos da natureza.

Compreendemos que a educação ambiental em si ainda é um campo em desenvolvimento e, provavelmente, sempre o será no sentido que os processos educativos precisam ser constantemente revistos e adequados às diferentes necessidades, tempos e realidades. Porém, entendemos que essa perspectiva de pesquisa soma, ainda mais, novos e enormes desafios, pois tomamos consciência, também, de coisas que são incompreensíveis ao nosso olhar e de uma vida em fluxo em um mundo em constante transformação. Isso aumenta o campo das incertezas, em geral negado nas pesquisas científicas. Por outro lado, são essas incertezas que abrem a possibilidade de nos (re)inventarmos, de um mundo novo sempre a ser descoberto, de um mundo que pode ser (re)criado e de uma maior adaptabilidade ao incerto e ao que está por vir. Compreendemos nossa agência, ao mesmo tempo em que compreendemos a inserção da malha de outras agências humanas e não humanas, o que nos situa em um papel ao mesmo tempo ativo e passivo, ou do mover-se e deixar-se mover.

Esperamos, por fim, que esta pesquisa possa somar esforços na defesa da necessidade de implantação e manutenção das áreas verdes urbanas. Pois, além dos motivos ambientais e ecológicos, já amplamente conhecidos e divulgados, e da necessidade de manutenção ecossistêmica no ambiente urbano, elas são igualmente importantes na constituição e desenvolvimento dos seres humanos em seus vínculos mais profundos, sendo também um direito dos demais seres que dividem a vida e o mundo conosco.

\section{Referências}

BRASIL. Resolução Conama $N^{o}$ 369, de 28 de março de 2006. Brasília: MMA, 2006. Disponível em <http://www.mma.gov.br/port/conama/legiabre.cfm?codlegi=489> Acesso em: 24/05/2016.

CARVALHO, I. C. M.; STEIL, C. A. O pensamento ecológico de Tim Ingold. Anuario de Antropología Social y Cultural en Uruguay, v. 10, p. 239-241, 2012.

CARVALHO, L. M. A temática ambiental e o processo educativo: dimensões e abordagens. In CINQUETTI, H. C. S; LOGAREZZI, A. (Orgs). Consumo e Resíduo: fundamentos do trabalho educativo, São Carlos: Ed. UFSCar, 2006, p. 19-42.

CENTRO REGIONAL DE INFORMAÇÃO DAS NAÇÕES UNIDAS (UNRIC). Relatório "Perpectivas da urbanização mundial de 2014". UNRIC, s/d. Disponível em https://www.unric.org/pt/actualidade/31537-relatorio-da-onu-mostra-populacao-mundial-cada vez-mais-urbanizada-mais-de-metade-vive-em-zonas-urbanizadas-ao-que-se-podem-juntar 25-mil-milhoes-em-2050. Acesso em: 03/02/2018.

EVANS, J.; JONES, P. The walking interview: Methodology, mobility and place. Applied Geography, p. 849- 858. v. 31, 2011. 
GRÜN, M. A importância dos lugares na educação ambiental. REMEA, v. especial, p. 1 -11, dez 2008.

HOFSTATTER, L. J. V. Biodiver-cidade: vivendo e experimentando o espaço urbano na educação ambiental para e com a biodiversidade. 186f. Tese (Doutorado em Ciências, área de concentração em Ecologia e Recursos Naturais). Universidade Federal de São Carlos, 2018.

HORTON, J.; CHRISTENSEN, P.; KRAFTL, P.; HADFIELD-HILL, S. Walking ... just walking': how children and young people's everyday pedestrian practices matter. Social \& Cultural Geography, v. 15, n. 1, p. 94-115, 2014.

IARED, V. G. A experiência estética no Cerrado para a formação de valores estéticos e éticos na educação ambiental. 173 p. 2015. Tese (Doutorado em Ciências) - Universidade Federal de São Carlos, São Carlos.

IARED, V. G.; OLIVEIRA, H. T. Walking ethnography e entrevistas na análise de experiências estéticas no Cerrado. Educação e Pesquisa, v.43, n4, julho 2017a.

IARED, V. G.; OLIVEIRA, H. T. O Walking Etnography para a compreensão das interações corporais e multissensoriais na educação ambiental. Ambiente \& Sociedade. v. XX, n. 3, p. 99116, jul.-set. $2017 \mathrm{~b}$.

INSTITUTO BRASILEIRO DE GEOGRAFIA E ESTATISTICA (IBGE). Censo Demográfico 2010. Brasília: $\quad$ IBGE, 2010. Disponível em: http://www.ibge.gov.br/cidadesat/topwindow.htm?1. Acesso em: 03 fev. 2018.

INGOLD, T. Estar vivo: ensaios sobre movimento, conhecimento e descrição (trad. Fábio Creder). Petrópolis, RJ: Vozes, 2015.

INGOLD, T. Da transmissão da representação à educação da atenção (trad. José Fonseca). Educação. Porto Alegre, v. 33, n.1, p. 6-25. jan/abr. 2010.

LAYRARGUES, P. P.; LIMA, G. F. C. Mapeando as macro-tendências político-pedogógicas da educação ambiental contemporânea no Brasil. In: VI ENCONTRO PESQUISA EM EDUCAÇÃO AMBIENTAL. Anais... Ribeirão Preto, set 2011. Disponível em: 〈http://www.epea.tmp.br/viepea/epea2011_anais/busca/pdf/epea2011-0127-1.pdf> Acesso em: 09 mar. 2017.

MINISTÉRIO DO MEIO AMBIENTE. Definição de áreas verdes urbanas (s/d.) Disponível em <http://www.mma.gov.br/informma/itemlist/category/61-areas-verdes-urbanas> Acesso em: 24 mai. 2016.

MERLEAU-PONTY, M. Fenomenologia da percepção (trad. Carlos Alberto Ribeiro de Moura). São Paulo: Martins Fontes, 1999.

MERLEAU-PONTY, M. O visível e o invisível (trad. José Artur Gianotti e Armando Mora d'Oliveira). São Paulo, SP: Perspectiva, 2014.

MURRIS, K. The Posthuman Child. In: KENNEDY, D.; BAHELER, B. (Editors). Phylosophy of childhood today: exploring the boundaries. Lanhan: Lexington books, 2017, p. 185- 197. 
OLIVEIRA, C. O ambiente urbano e a formação da criança. São Paulo: Aleph, 2004.

OLIVEIRA, A. G. et al. Mapeamento de índices de cobertura vegetal dos bairros de SalvadorBA com uso de imagens do sensor RapidEye para o ano de 2009. In: XVI Simpósio Brasileiro de Sensoriamento Remoto. Anais... Foz do Iguaçu, 2013, p. 818-825. Disponível em: <http://www.dsr.inpe.br/sbsr2013/files/p1405.pdf>. Acesso em: 03 abr. 2017.

PINK, S. Doing sensory ethnography. London, UK: Sage, 2009.

RUSS, A.; KRASNY, M. Urban environmental education trends. IN: RUSS A. (ed.). Urban environmental education. NY and Washington, DC: Ithaca, 2015, p. 12-25.

SOCIEDADE BRASILEIRA DE ARBORIZAÇÃO URBANA - SBAU. "Carta a Londrina e Ibiporã". Boletim Informativo, v. 3, n. 5, p. 3, 1996.

STEIL, C. A.; CARVALHO, I. C. M. Epistemologias ecológicas: delimitando um conceito. MAN, Rio de Janeiro, v. 20, n. 1, p.163-183, abril 2014.

THRIFT, N. Non-Representational Theory: space, politics, affect. New York: Routledge, 2008.

TUAN, Y-F. Topofilia: um estudo da percepção, atitudes e valores do meio ambiente. (trad. Lívia de Oliveira). Londrina, PR: Eduel, 2012.

TUAN, Y-F. Espaço e lugar: a perspectiva da experiência (trad. Lívia de Oliveira). Londrina, PR: Eduel, 2013. 